Current Issues in Middle Level Education

Volume 25 | Issue 1

Article 5

2020

\title{
We don't teach to the edTPA: Maintaining authenticity and attaining high edTPA scores
}

Holly J. Thornton

Appalchian State University, thorntonhj@appstate.edu

Follow this and additional works at: https://digitalcommons.georgiasouthern.edu/cimle

Part of the Junior High, Intermediate, Middle School Education and Teaching Commons

\section{Recommended Citation}

Thornton, Holly J. (2020) "We don't teach to the edTPA: Maintaining authenticity and attaining high edTPA scores," Current Issues in Middle Level Education: Vol. 25 : Iss. 1 , Article 5.

DOI: $10.20429 /$ cimle.2020.250105

Available at: https://digitalcommons.georgiasouthern.edu/cimle/vol25/iss 1/5

This best practices is brought to you for free and open access by the Journals at Digital Commons@Georgia Southern. It has been accepted for inclusion in Current Issues in Middle Level Education by an authorized administrator of Digital Commons@Georgia Southern. For more information, please contact digitalcommons@georgiasouthern.edu. 


\title{
We Don't Teach to the edTPA: Maintaining Authenticity and Attaining High edTPA Scores
}

\author{
Holly Thornton \\ Appalachian State University
}

\begin{abstract}
Concerns have been raised about the high-stakes nature of edTPA potentially leading to reductionist, test-driven approaches to teacher preparation. This has come to fruition in practice within many teacher preparation classrooms. EdTPA can devalue anything that is not formally assessed and limit opportunities for faculty and teacher candidates to imagine new possibilities for education (Madeloni \& Gorlewski, 2013). In middle level teacher preparation, we can build upon the connections found between AMLE standards (AMLE, 2012) and edTPA. This includes the goal of improving pedagogy through reflection, inquiry, and intentional design to positively impact student learning. As middle level education professors, we can define the language and focus of the edTPA assessment tool for ourselves and our teacher candidates. We can focus on relationships, responsiveness and professionally grounded decision making, instead of the rote procedures of didactic teaching, or the technical steps of "doing" the edTPA. Strategies to accomplish this as related to each of the tasks within edTPA are discussed in this article.
\end{abstract}

\section{Concerns about High Stakes Assessment}

EdTPA has become a mandated part of teacher preparation programs nationally. As of this writing, 927 Educator Preparation Programs in 41 states and the District of Columbia participate in edTPA, with 18 states requiring success on edTPA as part of their teacher licensure policy (AACTE, 2020). Concerns have been raised about the high-stakes nature of edTPA potentially leading to reductionist, test-driven approaches to teacher preparation. This has come to fruition in practice within many teacher preparation classrooms. The implementation of edTPA has led to some faculty and clinical educators "teaching to the test". The shift of student teaching seminars to focus heavily on completing edTPA rather than reflection on practice has exacerbated these concerns (Madeloni \& Gorlewski, 2013). Along with the shift in student teaching experiences, test preparation consumes more instructional time in courses that should be focused on methods and instruction (Greenblatt \& O'Hara, 2015). EdTPA can devalue anything that is not formally assessed and limit opportunities for faculty and teacher candidates to imagine new possibilities for education (Madeloni \& Gorlewski, 2013). Opportunities for student teachers to reflect about themselves, their students, schools, and the larger sociopolitical context of schooling can be limited by the prompts and rubrics of edTPA.

\section{Teaching as a Technical Act}

The definition of teaching a technical act is perhaps the most problematic impact of shifting to a "teach to the test" mindset in colleges of education. Attempts to quantify teacher 
quality are abundant and include value added scores, PRAXIS tests, and counting content related course hours. EdTPA has joined those ranks. EdTPA is an overwhelming 40+ page document with detailed instructions focused on directions and compliance (Madeloni \& Hoogstraten, 2013). The final product is submitted to a 'calibrated scorer' whose evaluation reduces student work to a number, without feedback. Preparation and performance on edTPA can easily be reduced to an act of "doing" rather than thinking.

Many of the tensions regarding edTPA have more to do with managing the technical and administrative demands of the assessment rather than authenticating or improving teaching practices. An overly administrative focus may overshadow accurate representation of candidates' potential as teachers. (Meuwissen \& Choppin, 2015). Concern has been expressed that the edTPA requirements may be viewed as hoop jumping and lead professors and teacher candidates to focus on going through steps. Teacher educators and researchers understand that teaching is far more than a compilation of technical skills. Middle level faculty need to address and resist that perception and reframe the narrative about edTPA.

\section{Pushing Back through Our Standards and Practices}

It is vital that teacher preparation faculty embrace strategic approaches that cause edTPA to become an intentional part of course design and instruction, rather than a tangentially related driving force. In middle level education we need to build connections between the edTPA process and our professional philosophies. The connections found between AMLE standards (AMLE, 2012) and edTPA include the goal of improving pedagogy through reflection, inquiry, and intentional design to positively impact student learning. Middle level education teaching standards have clear expectations for beginning teachers. Middle level teacher candidates learn how to reach and teach all young adolescent learners. Consideration of the assets and needs of diverse learners, social justice, and cultural and social awareness are embedded within our middle level philosophy. Language and tasks within edTPA allow us to center on the development of those considerations and foreground the importance of the multiple factors which influence students' construction of meaning in the classroom. EdTPA can demonstrate our programs' commitment to candidate performance of teaching standards, best practices, and research-based decision-making, that enable middle grades students to become successful learners and achieve goals. EdTPA should cause candidates to delve into why pedagogical choices are made and ground them in the middle level theory. Candidates also evidence the ability to design and justify instruction that deepens student learning and understanding through eliciting and building on students' responses that promote critical thinking. Candidates must make deliberate connections between their decisions as a teacher and the experiences, assets, and needs of the students they teach through video analysis of their teaching. Human connections in edTPA can also be found within rubrics that focus on how the teacher demonstrates rapport and understanding of students. An analysis of edTPA rubrics reveals the opportunity for focusing on relationships within the classroom and how this affects learning with young adolescents. This can be our focus rather than completing the technical aspects and "doing" edTPA.

\section{Strategies}

About three-fourths of the way through my senior level course one fall semester, my teacher candidates were concerned that I had not yet started to teach them about edTPA. This was the course prior to student teaching and their elementary counterparts had been going over edTPA handbooks and directions since the start of the semester. However, I had been using 
backwards design and scaffolding the ways of thinking, understanding, and making sense of teaching decisions that edTPA requires. I intentionally chose not to start by looking at edTPA handbooks and templates. Starting from this point creates a "doing" and technical mentality for students regarding edTPA. Embedding edTPA meaningfully within courses allows a focus on thinking and understanding, decision-making and young adolescent needs. I broke our required practice assessment, edTPA lite, into pieces and embedded the commentary questions in tasks as we learned. The students ended up doing well on edTPA because they had engaged in the type of thinking, grounding, justifying, and decision-making that edTPA requires. They were able to navigate how to submit edTPA and handle technicalities with less stress, since writing the "commentaries" had become second nature to them.

Intentional strategies can help candidates develop a perspective that edTPA is a way for them to show their understanding of how to be an effective middle level teacher, just a culminating assessment that captures what they already know and do. Embedding the kind of thinking required by edTPA in courses, rather than foregrounding passing it, can help. Thoughtfully weaving edTPA learning targets within our pre-service middle level courses can teach our students how to think about and cultivate meaningful student learning. It helps preservice teachers make sense of the complexities of teaching. The three sections of edTPA can be aligned with specific course activities and assessments.

The first section, planning, is easy to navigate. Instead of giving candidates a lesson plan format to use to "do" a plan, have candidates critique multiple approaches to lesson planning. Analyze how different plan formats show differing philosophies, how some are teacher-centered while others are not, and how decisions about planning impact students. This can tie into prior courses and later even in student teaching seminars. They can then analyze these lesson plans in terms of depth of learning using numerous taxonomies, such as Webb's Depth of Knowledge (2005) and the SOLO taxonomy (Biggs and Collis, 1982). Engaging them in backwards design as planning is also a good fit with the type of thinking the edTPA commentary emphasizes. Candidates focus on intentional lesson design to build on student diversities, allowing them to view differentiation beyond leveling and task modification. Candidates think about designing research-based lessons that enable young adolescents to demonstrate proficiency in meeting lesson objectives and learning targets.

EdTPA's second task is about instruction. This section requires candidates to analyze real teaching. I wanted my students to focus on how and why teachers make decisions in their classrooms, and ground them in the research, philosophy and practices we had studied within our courses. I model this "why level" thinking through talking about or asking my students why they thought I engaged them in various activities, or posed certain questions. This opens up the dialogue about my pedagogical thinking, and how this impacts their learning. Each student also tweeted about the why behind what we learned in class each day, making connections to research and best practices. Another potential strategy is using the writing process to direct candidates to rationalize their instructional decisions and support them with evidence, as an intentionally interpretive act (Meuwissen \& Choppin, 2015).

Clinical educators in our partner schools recorded and uploaded lessons to our course site. The candidates viewed the videos and used the commentary questions from edTPA to analyze each teacher's decisions. Following this analysis, each clinical educator met online with the candidates to discuss instructional and management decisions and to answer questions. The interactive use of these videos models how to analyze teaching and helps candidates to begin to 
view it as complex decision making instead of mechanical implementation. The experience becomes an opportunity for students to engage in dialogue with teachers highlighted in the videos, allowing them to talk together about the why behind teaching. These processes lead to collective deep thinking about teaching practices, before candidates have to teach their own lesson, and worry about recording it.

The third section of edTPA is about assessment. Education faculty embed multiple assessment approaches within coursework and often have specific courses on that topic. Two areas that I focus on related to edTPA are the concept of developing a meaningful quality rubric to assess learning and then providing meaningful feedback to students. The concept of assessment as evidence of learning that is scaffolded and directly tied to learning targets and objectives, vs just something you do at the end of a lesson or unit to get a grade, is important to successful thinking for edTPA. Critiquing rubrics is necessary, as many available rubrics are merely checklists and provide limited feedback to students. After watching and analyzing the clinical educators' lessons, the candidates receive student work samples from said lessons to evaluate. They create rubrics for evaluation of each lesson's goal . The candidates then give specific, focused feedback to individual students based on student misconceptions, successes, and depth of understanding. By reviewing and evaluating actual student work samples from the clinical educators' lessons, teacher candidates learn how to give in-depth feedback to specific students, analyze data across the class to reflect on successes, and determine next steps needed for responsive instruction. They learn to think as an assessor first, before they craft their own assessments and rubrics to use in actual classrooms for the practice edTPA.

\section{Conclusion}

Middle level teacher educators need to exploit the authentic nature of edTPA rather than perceiving it as a high-stakes test. If we choose not to reinforce perspectives that center on highstakes testing and technical implementation, perhaps some of the concerns about edTPA can be mitigated. The skills and abilities necessary to successfully engage edTPA tasks can be purposefully and legitimately interwoven within our preparation programs and are not unlike the negotiations candidates will encounter as a classroom teacher.

As professionals, we can define the language and focus of the edTPA assessment tool for ourselves. We can focus on relationships, responsiveness and professionally grounded decision making, instead of the rote procedures of didactic teaching, or the technical steps of "doing" the edTPA. Our students will be successful, not because we drilled them on how to do edTPA, but because the assessment will capture their thinking and understanding as new teachers. If we view teaching as decision-making and model this for our students, it is incumbent upon us, as middle level educators to once again take the lead in deciding how edTPA will impact our profession.

\section{References}

AACTE (2020) edTPA. Retrieved from: https://www.edtpa.com/PageView.aspx?f=GEN_AboutEdTPA.html. June 15, 2018 
Association for Middle Level Education. (2012). Middle Level Teacher Preparation Standards with Rubrics and Supporting Explanations. Accessed from: http://www.amle.org/AboutAMLE/ProfessionalPreparation/AMLEStandards.aspx.

Biggs, J. B., \& Collis, K. (1982). Evaluating the quality of learning: The SOLO taxonomy. Academic Press.

Greenblatt, D., \& O’Hara, K. (2015). Buyer beware: Lessons learned from EdTPA implementation in New York State. Teacher Education Quarterly, 42(2), 57-67.

Madeloni, B., \& Gorlewski, J. (2013). Radical imagination, not standardization: Critical teacher education and the edTPA. Rethinking Schools v27, n4. Retrieved from: http://www.rethinkingschools.org/archive/27_04/27_04_madeloni-gorlewski.html

Madeloni, B., \& Hoogstraten, R. (2013). The other side of fear.” Schools: Studies in Education, $10(1)$.

Meuwissen, K., \& Choppin J. (2015). Preservice teachers' adaptations to tensions associated with the edTPA during its early implementation in New York and Washington states. Education Policy Analysis Archives 23.

Webb, N. (2005). Depth-of-Knowledge levels for four content areas. Presentation to the Florida Education Research Association, 50th Annual Meeting, Miami, Florida. 